\title{
Inflammation, Endothelial Dysfunction and Arterial Stiffness as Therapeutic Targets in Cardiovascular Medicine
}

Vittoriano Della Corte, Antonino Tuttolomondo*, Rosaria Pecoraro, Domenico Di Raimondo, Valerio Vassallo and Antonio Pinto

\section{U.O.C di Medicine Interna e Cardioangiologia, Dipartimento Biomedico di Medicina Interna e Specialistica (Di.Bi. M.I.S), University of Palermo, Italy}

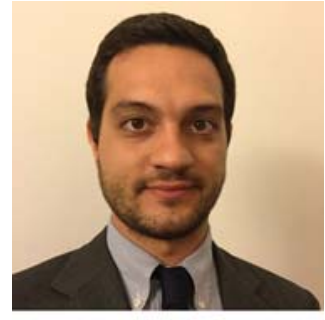

Vittoriano Della Corte

A R T I C L E H I S T O R Y

Received: March 18, 2016

Accepted: May 9, 2016

DOI: $10.2174 / 13816128226661605101$ 24801

\begin{abstract}
In the last decades, many factors thought to be associated with the atherosclerotic process and cardiovascular events have been studied, and some of these have been shown to correlate with clinical outcome, such as arterial stiffness, endothelial dysfunction and immunoinflammatory markers. Arterial stiffness is an important surrogate marker that describes the capability of an artery to expand and contract in response to pressure changes. It can be assessed with different techniques, such as the evaluation of PWV and AIx. It is related to central systolic pressure and it is an independent predictor of cardiovascular morbidity and mortality in hypertensive patients, type 2 diabetes, end-stage renal disease and in elderly populations. The endothelium has emerged as the key regulator of vascular homeostasis, in fact, it has not merely a barrier function but also acts as an active signal transducer for circulating influences that modify the vessel wall phenotype. When its function is lost, it predisposes the vasculature to vasoconstriction, leukocyte adherence, platelet activation, thrombosis and atherosclerosis. Non-invasive methods were developed to evaluate endothelial function, such as the assesment of FMD, L-FMC and RHI. Moreover in the last years, a large number of studies have clarified the role of inflammation and the underlying cellular and molecular mechanisms that contribute to atherogenesis. For clinical purposes, the most promising inflammatory biomarker appears to be CRP and a variety of population-based studies have showed that baseline CRP levels predict future cardiovascular events. Each of the markers listed above has its importance from the pathophysiological and clinical point of view, and those can also be good therapeutic targets. However, it must be stressed that assessments of these vascular markers are not mutually exclusive, but rather complementary and those can offer different views of the same pathology. The purpose of this review is to analyze the role of arterial stiffness, endothelial dysfunction and immunoinflammatory markers as surrogate endpoint, assessing the correlations between these markers and evaluating the therapeutic perspectives that these offer.
\end{abstract}

Keywords: Arterial stiffness, andothelial dysfunction, inflammation, atherosclerosis, pulse wave velocity, flow mediated dilation, low flow mediated constriction, $\mathrm{C}$ reactive protein.

\section{INFLAMMATION, ENDOTHELIAL DYSFUNCTION AND ARTERIAL STIFNESS AS SURROGATE ENDPOINTS: BACKGROUND}

In clinical trials, a surrogate endpoint (or marker) is "a biomarker intended to substitute for a clinical endpoint" in accordance with The National Institutes of Health (USA) definition [1,2]. A valid surrogate end point can become clinically important, replacing a clinical outcome if the effect of the intervention on the surrogate end point predicts the effect on the clinical outcome [3]. A surrogate endpoint is expected to predict clinical benefit, harm or lack of based on pathophysiological, therapeutic, epidemiologic, or other scientific evidence. Diagnosis and clinical trials are facilitated with surrogate endpoints because changes of these markers are detected earlier and at a lower cost than clinical endpoints (which consists in how an individual feels, functions or survives) [4].

A surrogate marker should meet the following criteria [5]:

- Adds independent information above currently used criteria.

- Is reliably and reproducibly measured.

- Accounts for a significant proportion of disease risk.

- Provides good predictive value.

- Is reasonably associated with the underlying pathophysiology.

*Address correspondence to this author at the Dipartimento Biomedico di Medicina Interna e Specialistica, Facoltà di Medicina e Chirurgia, Università degli Studi di Palermo, Italy, Piazza delle Cliniche n.2, 90127 Palermo, Italy; E-mail: bruno.tuttolomondo@unipa.it
- Is present before the clinical appearance of the outcome if it is to be used in risk prevention.

- Is practical and available for widespread application.

Epidemiological studies, such as Framingham, have allowed longitudinal assessment of cardiovascular events and the development of simple scoring tables for risk calculation [6,7]. These factors involved include blood pressure, low density lipoprotein cholesterol (and in general lipid profile), smoking status and age. The first two are classic examples of surrogate endpoint, indeed these are targets of treatment, and more recently many factors thought to be associated with the atherosclerotic process and cardiovascular events have been studied. Some of these have been shown to correlate with clinical outcome, such as carotid intima-media thickness (cIMT), Ankle-brachial index (ABI), arterial stiffness, endothelial dysfunction and immunoinflammatory markers. The purpose of this review is to analyze the role of arterial stiffness, endothelial dysfunction and immunoinflammatory markers as surrogate endpoint, assessing the correlations between these markers and evaluateing the therapeutic perspectives that these offer.

\section{ARTERIAL STIFFNESS}

Blood pressure measured with a cuff and sphygmomanometer in the brachial artery has long been known to be a prominent risk factor for cerebrovascular and coronary disease. While initial work concentrated on brachial pressure, more recently, it has been recognized that aortic (central) systolic pressure is better related to future cardiovascular events than is brachial pressure. Aortic systolic pres- 
sure is effectively lower than corresponding brachial values, in fact, while diastolic and mean arterial pressures are relatively constant along the arterial tree, systolic pressure may be up to $40 \mathrm{mmHg}$ higher in the brachial artery than in the aorta $[8,9]$. This phenomenon of systolic pressure "amplification" is due principally to an increase in arterial stiffness moving away from the heart. Arterial stiffness is an important surrogate marker that describes the capability of an artery to expand and contract in response to pressure changes [10]. Different models allow the description of systemic circulation mechanics. In the arterial waveform analysis model, flow and pressure waves are generated with each heartbeat and are conducted towards the periphery where they are reflected backwards (towards the heart) for various reasons (presence of bifurcations, stiffness gradient, abrupt diameter gradient in arterioles). On their return, the reflected waves merge with the antegrade wave and amplify it [11]. As a result of this mechanism (but not exclusively), peripheral blood pressures are higher compared to aortic (central) blood pressures to a varying degree, and this is the "amplification" phenomenon mentioned above [12]. The Augmentation Index (AIx) is a ratio calculated from the blood pressure waveform and it is a measure of wave reflection and arterial stiffness; AIx is commonly accepted as a measure of the enhancement of central aortic pressure by a reflected pulse wave [12-16]. Central blood pressures are more relevant than peripheral ones, as the heart, brain and kidneys are directly exposed to them [13]. With aging, the arrival of reflected waves in the ascending aorta is shifted into systole due to earlier wave return; this is largely explainable with an increased aortic stiffness and the resulting wave changes shape. This process determines an increased central systolic pressure (increased cardiac load and oxygen consumption), decreased diastolic pressure (lower myocardial perfusion pressure) and promotion of degeneration of the elastic components of the arterial wall. The net result is an imbalance towards myocardial ischaemia, an impairment of (mainly diastolic) left ventricular function, and other negative effects on brain and kidney. The processes described above allows to explain why aterial stiffness is correleted with central systolic pressure ad is an independent predictor of cardiovascular morbidity and mortality in hypertensive patients, type 2 diabetes, end-stage renal disease and in elderly populations [14]. The structure of subcutaneous small resistance arteries, as assessed by their media/lumen ratio, correlates both with wave reflections, stiffness of large conduit arteries [12-14] and BP levels. Large artery stiffness is correlated with cerebral microvascular disease (lacunar infarctions/large white matter hyperintensities) $[13,14]$. Using a non-invasive approach (scanning laser Doppler flowmetry) for assessing retinal arteriolar morphology, it has been showed that central pulse pressure and AIx correlate with wall/lumen ratio [12]. Such relationships sugest a coupling and crosstalk between micro- and macrovascular arterial beds [13] Increased media/lumen ratio and rarefaction of capillaries are early manifestations of target organ damage [14] as well as major factors for a raise in mean BP, which, in turn, increases large artery stiffness through the loading of stiff components of the arterial wall. The raised large artery stiffness amplifies pulse pressure, which, subsequently, damages small arteries of the heart, brain, retina and kidney. Thus, the crosstalk between small and large arteries exaggerates target organ damage, following a vicious circle [13]. A variety of invasive and non-invasive methods to measure arterial stiffness have been described. The most widely used and validated techniques involve the assessment of pulse waves as they travel over the arterial tree. Carotid-femoral pulse wave velocity (PWV), i.e. the velocity of the pulse as it travels from the heart to the carotid and the femoral artery, remains the most commonly used non-invasive method and is considered as the "gold standard" [14]. Cardio-ankle vascular index (CAVI) has been recently introduced, is mainly used in Japan and has the theoretical advantage to be less dependent on BP levels [4]. Arterial stiffness is determined in large part by the elastin to collagen ratio in their walls. The proximal large arteries (aorta and major branches) are prettyelastic due to high elastin content. Aging leads to progressive arterial stiffness as a consequence of elastic fibre degeneration. Increase in PWV with aging is found in populations with low prevalences of atherosclerosis, prompting that medial degeneration is an important cause of arterial stiffening [17]. One hypothesis is that repetitive cyclic stress over a lifespan determines the fracture of elastin fibres [18]. Other evidences on the molecular pathways suggests that ageing of the arterial media is associated with increased expression of matrix metalloproteinases (MMP), which are members of the zincdependent endopeptidase family and are involved in degradation of vascular elastin and collagen fibres [19]. Another view is that aortic stiffness occurs as a result of atherosclerosis over the aorta. However, there is little or no correlation between PWV and classical risk factors for atherosclerosis, other than age and blood pressure. Moreover, PWV does not raise during early stages of atherosclerosis, as assessed by intima-media thickness and non-calcified atheroma, but it does raise in the presence of aortic calcification that occurs within advanced atherosclerotic plaque [20]. Classic cardiovascular risk factors, including diabetes mellitus, hyperlipidaemia, smoking and elevated body mass index, have been concerned in accelerated arterial stiffening. However, findings regarding risk factors other than age and blood pressure have been inconsistent and negative findings not highlighted in many studies. Clustering of risk factors in the metabolic syndrome explains $<1 \%$ of PWV variance [21]. Moreover, a systematic review of publications assessing independent determinants of arterial stiffness indicated a poor correlation between PWV and established cardiovascular risk factors other than blood pressure and age [22]. This is in accordance with prospective studies where risk factors other than hypertension are not correlated with progression of PWV [23] PWV and the AIx have been shown to be predictors of cardiovascular events in hypertensive subjects [24]. Recent studies have also showed a correlation between PWV and C-reactive protein, independent of mean pressure and age [25]. The effect of cardiovascular drugs on measures of arterial stiffness has been extensively examined and reviewed [26]. Many of the agents also tested lower blood pressure, and this effect must be distinguished from any effects on structural remodelling or amelioration in endothelial function that would favourably affect arterial stiffness. Agents that decrease arterial stiffness include nitroglycerin [27] angiotensin-converting enzyme inhibitors and angiotensin receptor blockers [28] and calcium channel blockers [29]. The data for beta-blockers are not nearly as clear. Drugs that have advantageous effects on outcomes and endothelial function, such as statins, have been shown to reduce arterial stiffness, but further studies are needed in this area [30,31].

\section{ENDOTHELIAL DYSFUNCTION}

The endothelium is a single-cell lining covering the internal side of blood vessels. The endothelium has emerged as the key regulator of vascular homeostasis, in fact it has not merely a barrier function but also acts as an active signal transducer for circulating influences that modify the vessel wall phenotype [32]. A balance between endothelium-derived relaxing and contracting factors is critical in keeping vascular homeostasis. When this balance is lost, it predisposes the vasculature to vasoconstriction, leukocyte adherence, platelet activation, mitogenesis, pro-oxidation, thrombosis, impaired coagulation, vascular inflammation and atherosclerosis [33]. Therefore, alteration in endothelial function precedes the development of morphological atherosclerotic changes and can also conduce to lesion development and later clinical complications [34]. The importance of the endothelium was first identified by its effect on vascular tone. This is achieved by production and release of several vasoactive molecules that relax or constrict the vessel, as well as by response to and modification of circulating vasoactive mediators such as bradykinin and thrombin [35]. NO is the key endothelium-derived relaxing factor, which plays a pivotal role in preserving vascular tone and reactivity [36]. This gas diffuses to the vascular smooth muscle cells and activates guanylate cyclase, 
which leads to cGMP-mediated vasodilatation. Shear stress is a key activator of eNOS in normal physiology, and this adapts organ perfusion to changes in cardiac output [37]. Moreover, NO serves to inhibit platelet and white cell activation and keep the vascular smooth muscle in a nonproliferative state. NO is generated from Larginine by the action of endothelial NO synthase (eNOS) in the presence of cofactors such as tetrahydrobiopterin [38]. Tetrahydrobiopterin deficiency leads to an 'uncoupling of NOS' with the resultant production of potent oxidants such as superoxide and hydrogen peroxide instead of NO. Superoxide inactivates NO to peroxynitrite, further decreasing NO activity in this uncoupled state. Cardiac risk factors in general lead to an increase in oxidative stress, attenuating net NO bioactivity and leading to endothelial dysfunction [39]. Prostacyclin, derived by the action of the cyclooxygenase system, is another endothelium-derived vasodilator that work independently of $\mathrm{NO}$ [40]. Although it may contribute to some of the other regulatory roles of the endothelium, it seems to have a more limited role in the maintenance of vasodilator tone in humans. The endothelium modulates vasomotion also by an increase in constrictor tone via generation of endothelin and vasoconstrictor prostanoids, as well as via conversion of angiotensin I to angiotensin II at the endothelial surface $[41,42]$. These vasoconstrictor agents predominantly act locally, but may also exert some systemic effects and have a role in the regulation of arterial structure and remodeling. A multitude of techniques to evaluate endothelial function have been described. There were developed noninvasive methods that for their ease of use permits implementation in clinical practice beyond vascular laboratories, and invasive methods requiring high levels of technical expertise (Such as coronary endothelial function) [43]. Among non-invasive methods, the most widespreaded and used is the assesment of flow-mediated dilation (FMD) on the brachial artery. FMD is an endotheliumdependent, NO-mediated process that exploits high-resolution ultrasound in the brachial artery by means of a high frequency linear transducer to monitor changes in arterial diameter in response to raised blood flow, an important physiological stimulus for endothelial NO production [44]. In brief, images are acquired at baseline and after deflation of a cuff inflated to at least $50 \mathrm{mmHg}$ above systolic BP [45] or at about $250 \mathrm{mmHg}$ [46] for a set length of time, usually 4-5 min. Placement of the cuff above or below the elbow has been the subject of controversy; When the cuff is placed on the upper part of the arm, reactive hyperemia typically elicits a greater percent change in diameter compared with that obtained by the placement of the cuff on the forearm [46-48]. This may be due to a greater flow stimulus resulting from recruitment of more resistance vessels or possibly to direct effects of ischemia on the brachial artery. FMD is defined as the maximum percent increase in arterial end-diastolic diameter during the first minutes of hyperaemia compared with the diameter at rest [45]. FMD measured in the forearm provides information which predicts the extent and severity of coronary atherosclerosis [49], correlates with coronary endothelial function, [50,51] and has prognostic implications that are similar to those of endothelial function measured invasively in the coronary circulation [52]. Numerous studies have incorporated FMD measurements because it improves rapidly with physiological and pharmacological interventions (e.g. statins, ACE-Is, calcium channel blockers, exercise, weight loss, estrogen, antioxidants, vitamins, dietary constituents). This reinforces the concept that endothelial dysfunction, the earliest stage of atherosclerosis, is a reversible process [52-54]. Nevertheless, whether an improvement in FMD with treatment may also translate into better clinical outcomes has not been assessed in a randomized controlled trial. In nonrandomized controlled studies, FMD improvement was associated with a reduction in events in hypertensive postmenopausal women [55] whereas persistent FMD impairment despite optimized therapy was associated with an increase in CV events [56]. A characteristic intrinsic to the concept of FMD is that it offers information about the 'recruitability' of endothelial vasomotor function (i.e. its respon- siveness to a specific stimulus), but it does not provide information concerning basal endothelial function (i.e. release of endothelial autacoids before FMD measures are initiated). We cannot exclude that an impaired responsiveness to an endothelial stimulus (i.e. an impaired FMD) may result from pre-existing vascular (endothelial) activation, rather than from endothelial dysfunction. An artery that is already activated (and dilated) would logically show a smaller FMD, independent of the presence of disease. The introduction of low-flow-mediated constriction (L-FMC) is an attempt at addressing this limitation. When the pneumatic cuff commonly used in FMD studies is inflated, an immediate decrease in blood flow occurs in the region proximal to the cuff. This low-flow state, and the parallel reduction in shear stress, are associated with a reproducible vasoconstriction, whose magnitude is proportional to the decrease in blood flow [57,58] Findings to date suggest that L-FMC is determined by release of the vasoconstrictor endothelin-1 and by inhibition of the release of cyclooxygenase-dependent products and endothelium-derived hyperpolarizing factor $[59,60]$. Since L-FMC occurs in response to a decrease in shear stress and is determined by endothelial mediators, one can hypothesize that it could complement FMD in two ways: first, because it provides a measure of resting endothelium-dependent vascular tone; and secondly, because, when combined with FMD responses, it may allow the description of an integrated score of basal and stimulated vascular function. Gori et al. measured Flow-mediated dilation (FMD) and low-flow-mediated constriction (L-FMC) in 451 consecutive patients before coronary angiography. Low-flow-mediated constriction $(\mathrm{P}<0.0001)$ and FMD $(\mathrm{P}=0.0005)$ progressively decreased with the number of diseased vessels, and L-FMC showed a significant linear association with the SYNTAX score $(\mathrm{R}=0.38 ; \mathrm{P}<0.0001)$. Reclassification statistics showed that the introduction of FMD to the model based on the traditional risk factors correctly reclassified an additional $5 \%$ of patients, and that the introduction of L-FMC net correctly reclassified $19 \%$ of the patients. There was no association between different parameters of endothelial function [61]. Noninvasive, finger probe-based methods exist for endothelial function evaluation. The most widely used is endothelial peripheral arterial tonometry (EndoPAT). EndoPAT is based on the measurement of pulsatile volume changes at the fingertip using a patented device (Itamar Medical, Caesarea, Israel). Tests can be made with the patient positioned either supine or sitting, with the sensors placed on the index finger of each arm. The endothelium-mediated changes in the finger vasculature elicited by a 5-min occlusion of the brachial artery are measured, using a standard BP cuff inflated to a suprasystolic pressure. When the cuff is suddenly released, the surge of blood flow causes an endothelium-dependent FMD. The dilation is recorded by the device as an increase in amplitude of the peripheral arterial tonometry signal. A post-occlusion to pre-occlusion ratio is calculated (called Reactive Hyperemia Index, RHI). Because the signal is also influenced by additional, non-endothelial dependent factors, those are corrected by measurements in the contralateral arm. The pathophysiological background of EndoPAT is similar to that of brachial FMD, since both evaluate endothelial function. Nevertheless, several studies have showed low to moderate correlation between the two methods, suggesting that FMD and EndoPAT provide distinct information regarding vascular function [61-64]. These findings may be explained by the corrections implemented in the EndoPAT, whilst no such correction is incorporated in the brachial FMD method, and by the difference in type of vessels measured: small arteries and microcirculation in the case of EndoPAT versus single conduit vessel in the case of brachial FMD [63-72].

\section{INFLAMMATION}

In the last decades a large number of studies have clarified the role of inflammation and the underlying cellular and molecular mechanisms that contribute to atherogenesis [70-72]. In a variety of animal models of atherosclerosis but in humans as well, blood leukocytes, mediators of host defenses and inflammation, localize in 
the earliest lesions of atherosclerosis [73]. The endothelium under normal conditions does not generally support binding of white blood cells. However, some studies have shown that early after initiation of an atherogenic diet, patches of arterial endothelial cells begin to express on their surface selective adhesion molecules that bind to diferent classes of leukocytes [73]. Particularly, vascular cell adhesion molecule-1 (VCAM-1) binds exactly the types of leukocytes found in early human and experimental atheroma, the $\mathrm{T}$ lymphocyte and monocyte. Not only does VCAM-1 expression raise on endothelial cells overlying nascent atheroma, [73] but mice genetically engineered to express defective VCAM-1 show interrupted lesion development [74]. Interestingly, the foci of increased adhesion molecule expression correspond with sites in the arterial tree particularly prone to generate atheroma. Considerable evidence suggests that impaired endogenous atheroprotective mechanisms occur at branch points in arteries, where the endothelial cells experience disturbed flow [75]. For example, a turbulent blood flow may decrease local production of endothelium-derived NO. This endogenous vasodilator molecule also has anti-inflammatory properties and can reduce expression of VCAM-1 [76] In addition to inhibiting natural protective mechanisms, disturbed flow can raise the production of some leukocyte adhesion molecules (eg, intercellular adhesion molecule-1 [ICAM-1]) [77]. Leukocytes adherent to the endothelium can penetrate into the intima. Recent research has discovered candidate chemoattractant molecules responsible for this transmigration. For example, monocyte chemoattractant protein-1 (MCP-1) seems to be responsible for the direct migration of monocytes into the intima at sites of lesion formation [78,79]. A family of T-cell chemoattractants may likewise call lymphocytes into the intima [80]. Blood-derived inflammatory cells that are resident in the arterial wall, participate and perpetuate a local inflammatory response. The macrophages express scavenger receptors for altered lipoproteins, enabling them to ingest lipid and become foam cells. In addition to MCP-1, macrophage colony-stimulating factor (MCSF) contributes to the differentiation of the blood monocyte into the macrophage foam cell [81-83]. T cells similarly encounter signals that cause them to generate inflammatory cytokines such as $\gamma$ interferon and lymphotoxin (tumor necrosis factor [TNF]- $\beta$ ) that in turn can induce macrophages as well as vascular endothelial cells and smooth muscle cells (SMCs) [83]. As this inflammatory process continues, the activated leukocytes and intrinsic arterial cells can release fibrogenic mediators, including a variety of peptide growth factors that can promote replication of SMCs and contribute to generation by these cells of a dense extracellular matrix which is typical of the more advanced atheroma [84]. Inflammatory processes is critical not only in promoting initiation and evolution of atheroma, but also to contribute decisively to precipitating acute thrombotic complications of atherosclerotic lesions. Most coronary arterial thrombi that cause fatal acute myocardial infarction result from a physical disruption of the atherosclerotic plaque. The activated macrophage in atheroma can produce proteolytic enzymes capable of degrading the collagen that gives strength to the plaque's protective fibrous cap, leading to thinning and weaking of that cap that becomes susceptible to rupture. C-reactive protein (CRP) is, at present, the only circulating biomarker related to vascular wall biology with a large body of published studies supporting its clinical use for risk stratification. Other novel circulating biomarkers, including oxidized low-density lipoprotein [85] and dysfunctional high-density lipoprotein, [86] have a future potential for prevention but at this time they have limited bench-to-bedside implementation. High-sensitivity CRP (hsCRP) is a marker of systemic inflammation that is up regulated as a result of vascular disease. Recent data showed that apart from its hepatic origin, CRP is present in both atherosclerotic plaques and injured vessel walls, which are involved in its secretion for small amounts [87]. Growing evidence suggests that in acute coronary syndrome (ACS), increased circulating inflammatory markers, in particular C-reactive protein (CRP), predict an unfavorable course, independent of the severity of the athero- sclerotic or ischemic burden. Thus, inflammation represents one potential new pathophysiological mechanism of the ACS that may provide such a new target for therapy. Liuzzo et al. [88] demonstrated early on that increased CRP correlates with adverse shortterm prognosis in selected patients with unstable angina, Braunwald class IIIb, who lacked evidence of myocardial necrosis and had an ischemic burden similar to that of patients without CRP elevation. Half of patients with ACS have persistently elevated CRP after discharge, and this evidence is associated with recurrent episodes of instability and infarction [89]. Inflammation might not only indicate increased risk of infarction, but also contribute in precipitating occlusive events. Furthermore, the acute-phase inflammatory response may directly affect thrombosis. Although CRP serves as a useful marker of inflammation, the other proteinsincreased during the acute-phase response include fibrinogen and plasminogen activator inhibitor-1. Thus, inflammation can promote thrombus formation and can enhance clot stability by inhibiting endogenous fibrinolysis. In addition to the ACS, inflammation contributes across the spectrum of cardiovascular disease, including the earliest steps in atherogenesis. This acknowledgment has had a important impact on our understanding of atherothrombosis as more than a disease of lipid accumulation, but rather as a disorder characterized by lowgrade vascular inflammation. In clinical practice, we can use this recognition to predict future cardiovascular risk. To date, increased levels of a variety of inflammatory mediators among apparently healthy men and women have proven to have predictive value for future vascular events. Particularly, prospective epidemiological studies have found increased vascular risk in association with elevated basal levels of cytokines such as IL-6 and TNF- $\alpha$; [90-93] cell adhesion molecules such as soluble ICAM-1, P selectin, and E selectin [94-97] and downstream acute-phase proteins such as CRP, fibrinogen and serum amyloid A [90,98-104]. For clinical purposes, the most promising inflammatory biomarker appears to be CRP [105]. CRP has a long half-life, affording stability of levels with no observable circadian variation and is easily measured in usual outpatient settings [106,107]. A variety of population-based studies have showed that baseline CRP levels predict future cardiovascular events. CRP testing may thus have a major adjunctive role in the global assessment of cardiovascular risk [108]. The Cholesterol and Recurrent Events (CARE) trial was a secondary prevention study in which elevated CRP levels was associated with significantly elevated risk of recurrent coronary events [109]. In a series of hypothesis-generating studies, the CARE investigators then found that the magnitude of risk reduction attributable to pravastatin was substantially greater among those with evidence of inflammation compared with those without evidence of inflammation. The CARE investigators also showed that random allocation to pravastatin lowered CRP levels in a manner unrelated to the effect of pravastatin on LDL or HDL cholesterol, data that presented strong evidence that statins may have important anti-inflammatory effects $[109,110]$. Clinical studies with cerivastatin, lovastatin, simvastatin, and atorvastatin have since replicated the reduction in CRP first described in the CARE trial for pravastatin [111-114]. Whether CRP may play a role as an adjunct to lipid screening or as a tool to improve targeting of statin therapy, was assessed in the Air Force/Texas Coronary Atherosclerosis Prevention Study (AFCAPS/TexCAPS) [115] In brief, CRP levels were evaluated at baseline among 5742 participants in AFCAPS/TexCAPS, a primary prevention study of lovastatin carried out among low- to moderaterisk individuals. This study showed an overall reduction in primary acute coronary events of $37 \%$ [116]. Random allocation to lovastatin therapy was highly effective in reducing primary acute coronary events among those with baseline levels of LDL cholesterol above $149 \mathrm{mg} / \mathrm{dL}$, the median LDL value in the cohort as a whole. However, lovastatin therapy also reduced coronary event rates among those with lower levels of LDL cholesterol and abovemedian levels of CRP. In marked contrast, lovastatin therapy did not benefit participants in the AFCAPS/Tex- CAPS trial who had 
below-average LDL levels and belowaverage CRP levels [112]. The CRP data from AFCAPS/ TexCAPS confirms that elevated CRP levels strongly predict future vascular risk and that the addition of CRP to lipid screening helps to predict global risk. Furthermore, these data raise the possibility that statin therapy may prove highly effective even among apparently healthy individuals who do not have hyperlipidemia, but who have a propensity toward coronary events as detected by elevated levels of CRP. As nearly 25000000 Americans fit within this low-LDL/high-CRP category yet remain outside current preventive guidelines, more specific understanding of the predictive role of elevated CRP in the presence of low LDL is needed [116].

\section{RELATIONSHIP BETWEEN ARTERIAL STIFFNESS, ENDOTHELIAL DYSFUNCTION AND INFLAMMATION}

As seen above, arterial stiffness and endothelial dysfunction represent different aspects of vascular disease, indeed there is little or no correlation between PWV and classical risk factors for atherosclerosis, other than age and blood pressure [21,22]. However, there is some kind of crosstalk between these two pathophysiological processes. NO is continuously produced and released by the endothelium and contributes to arterial compliance [117]. Some pharmacological agents that improve endothelial function, such as statins and angiotensinconverting enzyme inhibitors, also reduce arterial stiffness. This can be explained with a favourable effects on endothelial-derived paracrine factors, structural remodelling and direct effects on blood pressure [118]. In some studies it was measured the AIx from a peripheral artery at baseline and then in response to an inhaled beta2-agonist (endothelium-dependent). A lowering in the AIx was noted and this was blocked by NOS inhibition. In addition, the response was blunted in subjects with coronary artery disease or hypercholesterolemia $[119,120]$. Arterial stiffness has also been showed to be related to brachial artery FMD vasodilation in a recent small study [121]. And finally, a study by Mitchell et al. [122] has challenged our thinking about the effect of risk factors on brachial endothelial function. In a large cohort from Framingham, it was showed that hyperemic-induced shear stress was a prominent predictor of brachial FMD. In addition, risk factors reduced the magnitude of shear stress, suggesting that a diminished stimulus explains the reduction in endothelial function in subjects with cardiovascular risk factors [122]. In the study from Gori et al. FMD was assessed in the radial artery, and all of the subjects were vasoconstricted during cuff inflation (a response they termed low flow-mediated constriction) [60]. However, additional work has shown both varied and non-existent vessel responses when the tests were conducted in the brachial [123-125]. Currently, it remains controversial as to how the brachial artery responds to the low flow state created by cuff inflation, and it is unknown which factors influence this vessel response and whether this should be a consideration in the evaluation of endothelial function. In the study from Harrison et al. about 46 subjects with varying CAD risk factor profiles, there were assessed FMD and L-FMC in the brachial artery and it was observed a wide range of L-FMC values that varied from $-5,6 \%$ (vasoconstriction) to $5,0 \%$ (vasodilation). This demonstrates that while some subjects vasoconstricted, others vasodilated and some exhibited no change. Using absolute 0 as a cut-off, $59 \%$ of subjects vasoconstricted and $41 \%$ vasodilate [126]. In this study authors created a third measure, termed "modified FMD", to represent the effect of using the inflation diameter rather than the baseline diameter for the calculation of FMD. L-FMC and traditional FMD were not different between healthy and multiple risk factor groups (L-FMC: $-1,8 \pm 0,8 \%$ versus $-1,1 \pm 0,4 \%, \mathrm{P}=0,42$; FMD: $4,6 \pm 0,8 \%$ versus $3,8 \pm 0,5 \%, \mathrm{P}=0,39)$. The modified FMD was significantly higher in the healthy group than in the multiple risk factor group $(7,6 \pm 0,9 \%$ versus $4,9 \pm 0,6 \%, P=0,02)$. L-FMC was modestly but significantly correlated with FMD $(\mathrm{r}=0,41, \mathrm{P}<0,05)$ and was positively and significantly associated with brachial PWV $(r=0,30, P<0,05)[126]$. The discrepancy in the prevalence of con- striction between the study from Harrison et al. and that from Gori et al. may be explained by the imaging at different vascular beds. In the study from Gori et al. FMD was assessed in the radial, rather than the brachial, artery $[60,126]$. The brachial artery is the artery of choice for the measurement of FMD as it has been proven to be both accurate and reproducible, [127] and endothelial function in the brachial artery has been shown to correlate well with endothelial function in the coronary arteries [128]. A recent study is insightful in this context as they reported that vasoconstriction occurred in the radial artery in response to cuff inflation but not in the brachial artery [125] perhaps because of radial artery response to reperfusion during FMD measurement not being nitric oxide dependent $[9,129]$. In the study from Harrison et al. statistical significance between the healthy group and the multiple risk factor group was achieved only with the modified FMD. Therefore, modified FMD, which takes occlusion diameter into account, may be a better experimental approach from the theoretical standpoint as it represents the actual state of the vessel when it responds to the hyperaemic blood flow associated with cuff release. It was also showed a modest association between L-FMC and traditional FMD $(r=0,41)$. This relation suggests that the greater the vasoconstriction during cuff inflation, the lower the calculated FMD. This may provide some insight into the interplay between these two responses [125]. A positive association between L-FMC and FMD suggests that the endothelial mediators that control L-FMC (e.g. endothelin-1) may be still active and could interfere with the mediators responsible for the FMD reperfusion response (e.g. nitric oxide). One possibility that could account for this variable response to inflation of the cuff is the stiffness of the artery. As arterial stiffness raises, the ability of the brachial artery to vasoconstrict during cuff inflation would decrease as a result of a less compliant, stiffer vessel. Consistent with this hypothesis, Harrison et al. found a modest but significant correlation between L-FMC and brachial PWV $(r=0,30)$. These results suggest that arterial stiffness may play a role, at least in part, for determining the magnitude of L-FMC. The stiffness of central elastic arteries increases with ageing and disease state whereas peripheral muscular arteries, including brachial arteries, do not exhibit similar arterial stiffening [130,131]. Therefore, the stiffness of peripheral arteries may not be considered to be important from the clinical standpoint. However, the results from Harrison et al. study indicate that a local measure of arterial stiffness, as estimated by brachial PWV, explains some portion of the individual differences in L-FMC [126].

Regarding the relationship between arterial stiffness and inflammation, multiple potential mechanisms have been suggested by which inflammation could have an effect on arterial stiffness. Some of these mechanisms could induce rapid changes in the stiffness of large arteries through functional effects on the arterial endothelium or smooth muscle cells, thus explaining the effect of acute inflammation on large artery stiffness [132]. However, a variety of mechanisms can also link chronic low-grade inflammation with structural changes in the arterial wall. The activation of NADPH oxidase by inflammatory cytokines, such as TNF- $\alpha$ and IL-1, creates a milieu of increased oxidative stress that influences endothelial function through mechanisms other than NO. Superoxide and hydrogen peroxide stimulate mitogen activated protein kinases, specifically, serine threonine kinase/protein kinase $\mathrm{B}$ (Akt/PKB), leading to hypertrophy and increased survival of vascular smooth muscle cells [133] and trigger matrix metalloproteinases (MMP), the effects of which are discussed below [134]. Vascular superoxide production has been shown to correlate with aortic compliance, [135] augmentation index [132] and endothelial reactivity [136,137]. Inflammation may induce structural changes in arterial wall through the breakdown of elastin, proliferation of smooth muscle cells, and changes in the composition of the extracellular matrix [138-141]. Several studies have assessed the association between carotidfemoral PWV (cfPWV) and various inflammatory markers. In the largest available study assessing cfPWV, Schnabel et al. reported 
et al. reported an association between interleukin-6 (IL-6) and cfPWV in the Framingham Offspring cohort [142]. An association between CRP and cfPWV was observed in studies on Caucasian middle-aged [143] and older individuals [144] with low burden of cardiovascular risk factors as well as hypertensive adults. Interestingly, large studies in Chinese and black South-African populations have failed to show an association between CRP and cfPWV, suggesting that race/ethnicity may modulate this relationship. Multiple studies have shown elevated indices of arterial stiffness in subjects with primary inflammatory disorders and prospective studies (including 2 RCTs) [132] have generally demonstrated reductions in arterial stiffness following treatment with anti-TNF and other anti-inflammatory agents. However, at this time, there is not enough evidence to support the use of immunosuppressive agents for the purpose of cfPWV reduction.

It has been known for several years that the mechanisms of inflammation are implicated in causing endothelial dysfunction. Inflammatory cytokines impair vasodilatory responses by affecting NO production, while the reactive oxygen species generated in the inflammatory process further consume existing NO [145]. Creactive protein has also been shown to directly decrease eNOS expression, thus decreasing NO production [146,147]. The correlation between inflammation and endothelial dysfunction may be going seem obvious, however Sampaio et al. showed that, in a population of 47 nonsmoker women with a BMI of $32.37 \pm 5.06$ $\mathrm{kg} / \mathrm{m}^{2}$, there was no correlation between CRP and endothelial dysfunction $\left(r_{s}=0.08, P=0.64\right)$ [147]. The lack of association between CRP and endothelial function in overweight and obese women brings new questions and hypotheses: 1) it is possible that the level of eNOS dysfunction associated with increased CRP is not enough to lead to macroscopic changes and compromise vasodilatation; 2) considering that the increase in CRP was moderate and that endothelial function was considered within normal limits, maybe they were really a population of obese with no impaired vascular function enough to change an imaging method of assessing subclinical atherosclerosis [147,148].

\section{PERSONAL EXPERIENCES}

Our group evaluated vascular markers such as arterial stiffness, endothelial dysfunction and inflammation in the context of ischemic stroke, with particular attention to the differences found between diagnostic subtype of ischemic stroke classified according to the TOAST classification, reaching interestin results. TOAST classification distinguishes the following diagnostic subtypes [15].

1) Large-Artery AtheroSclerosis (LAAS). Defined as cortical or cerebellar lesions and brain stem or subcortical hemispheric infarcts usually (but not always) greater than $1.5 \mathrm{~cm}$ in diameter on CT or MRI associated with evidence by duplex imaging or arteriography of significant $(>50 \%)$ stenosis or occlusion of a major brain artery or branch cortical artery, presumably due to atherosclerosis.

2) Cardio-Embolic Infarct (CEI). Defined as clinical and brain imaging findings similar to those described for large-artery atherosclerosis associated with at least one cardiac source for an embolus (such as atrial fibrillation) and absence of largeartery atherosclerotic sources of thrombosis or embolism.

3) LACunar infarct (LAC). Defined as traditional clinical lacunar syndromes associated with a normal CT/MRI examination or a relevant brain stem or subcortical hemispheric lesion with a diameter of less than $1.5 \mathrm{~cm}$ demonstrated.

4) stroke of Other Determined Etiology (ODE). This category includes patients with rare causes of stroke, such as nonatherosclerotic vasculopathies, hypercoagulable states, or hematologic disorders; patients in this group have clinical and CT or MRI findings of an acute ischemic stroke, regardless of the size or location; cardiac sources of embolism and largeartery atherosclerosis should be excluded by other studies.

5) stroke of UnDetermined Etiology (UDE). In some cases, the cause of a stroke cannot be determined with any degree of confidence; some patients have no likely etiology determined despite an extensive evaluation, in others, no cause is found but the evaluation was cursory.

In a first study we enrolled 107 patients with acute ischemic stroke admitted to the Internal Medicine Department at the University of Palermo and 102 control subjects matched for age, sex, cardiovascular risk factors and previous cardiovascular morbidity. In both patients and controls Carotid-femoral pulse wave velocity (PWV) was evaluated by Applanation tonometry (SphygmoCor) and the aortic pressure waveform was used to calculate the Augmentation index (AIx). Stroke patients, compared to subjects without acute ischemic stroke, showed a higher mean AIx $(103 \pm 3.5 \mathrm{mmHg}$ vs. $99 \pm 4.6 \mathrm{mmHg})$ and $\mathrm{PWV}(11.8 \pm 3.3 \mathrm{~m} / \mathrm{s}$ vs. $10.02 \pm 2.29 \mathrm{~m} / \mathrm{s}$ ) [16]. Augmentation Index (AIx) and PWV values in lacunar subjects $(112 \pm 5.5 \% ; 11.98 \pm 2.445 \mathrm{~m} / \mathrm{s})$ were significantly higher compared to values observed in LAAS $(108 \pm 3.5 \%$; $5.80 \pm 0.445 \mathrm{~m} / \mathrm{s})$, CEI $(104 \pm 3.5 \% ; 10.40 \pm 2.445 \mathrm{~m} / \mathrm{s})$ and ODE $(105 \pm 3.5 \% ; 11.48 \pm 1.345 \mathrm{~m} / \mathrm{s})$ subtypes [16]. Subsequentely, in another study we evaluated the relationship between arterial stiffness indexes and immuno-inflammatory pathway in patients with an acute cardiovascular or cerebrovascular event. We assessed in 107 subjects with acute ischemic stroke and in 107 controls without stroke plasma levels of C-reactive protein (CRP), interleukin-1beta (IL-1 $\beta)$, tumor necrosis factor-alpha (TNF- $\alpha$ ), interleukin-6 (IL-6) and interleukin-10 (IL-10), E-selectin, P-selectin, intercellular adhesion molecule-1 (ICAM-1), vascular cell adhesion molecule-1 (VCAM-1), von Willebrand Factor (vWF), tissue plasminogen activator (TPA), plasminogen activator inhibitor-1 (PAI-1), carotidfemoral pulse wave velocity (PWV) and augmentation index (Aix). There was a significant positive relationship, corrected for age, and gender, between PWV and CRP $(r=0.36 ; \mathrm{P}<0.001)$, TNF- $\alpha(\mathrm{r}=$ $0.42 ; \mathrm{P}<0.001)$, IL1 $\beta(\mathrm{r}=0.35 ; \mathrm{P}<0.001)$, VWF $(\mathrm{r}=0.46 ; \mathrm{P}<$ $0.001)$, and IL-6 $(\mathrm{r}=0.27 ; \mathrm{P}<0.05)$ [97]; the AIx was significantly related, after correction for age and gender, to VWF $(\mathrm{r}=0.38$; $\mathrm{P}<$ $0.0001)$, but not to CRP ( $\mathrm{r}=0.09 ; \mathrm{P}=0.37)$, IL-6 ( $\mathrm{r}=0.12 ; \mathrm{P}<$ $0.08)$, or TNF- $\alpha(\mathrm{r}=0.14 ; \mathrm{P}<0.15)$ levels [97]. Among Lacunar subtype PWV, after correction for age and gender, was significantly and positively related to CRP, IL- $1 \beta$, IL-6, TNF- $\alpha$ and vWF. In subjects with stroke classified as LAAS, PWV was significantly and positively related to CRP, IL- $1 \beta$, IL- 6 , TNF- $\alpha$ but not with vWF. In CEI subtype, PWV was significantly and positively related to TNF- $\alpha$ and vWF but not with CRP, IL-6, IL-1 $\beta$. Among Lacunar and CEI subtype Aix was positively and significantly related, after correction for age and gender, only to vWF; in LAAS subgroup this relationship was significantly weaker and only close to statistical significance [97]. These findings show that lacunar infarct is the "stiffer" subtype of stroke and that both aortic stiffness and wave reflection are related to the degree of systemic inflammation in stroke subjects, suggesting that circulating inflammation mediators can influence the stiffness of vessels distant to those involved in the disease process itself. In 2012, we conducted a study to evaluate arterial stiffness markers in subjects with acute ischemic stroke and metabolic syndrome. We enrolled 130 patients with acute ischemic stroke and metabolic syndrome, 127 patients with acute ischemic stroke without metabolic syndrome and 120 control subjects without acute stroke, applanation tonometry was performed to record pulse wave velocity (PWV). Stroke patients with metabolic syndrome, compared control subjects without stroke showed higher PWV [149]. In subjects with ischemic stroke and metabolic syndrome, PWV was more significantly and positively correlated with body mass index, systolic blood pressure, hypertension, diabetes, glucose blood levels, LDL cholesterol levels, total cholesterol levels, micro-albuminuria, carotid plaque, previous brain infarct at 
neuro-imaging. These findings underline important role of both small vessel disease and atherosclerosis on arterial stiffness pathogenesis in the clinical setting of metabolic syndrome [149]. In the wake of these results, in 2014 we evaluate the associations between arterial stiffness indexes and immune-inflammatory markers in subjects with acute ischemic stroke with and without metabolic syndrome [150]. In subjects with acute ischemic stroke and metabolic syndrome compared to subjects with acute ischemic stroke without metabolic syndrome and control subjects we observed higher median plasma values of IL-1-beta $[10(6-11) \mathrm{pg} / \mathrm{ml}) v s .8$ (5-16) $\mathrm{pg} / \mathrm{ml}$ vs. 4 (2-5) pg/ml; $\mathrm{p}<0.001]$; IL-6 [12 (9-31) pg/ml) vs. 10.3 (7-29) pg/ml vs. 8 (3.1-12) pg/ml; $\mathrm{p}<0.001] ; \mathrm{TNF}-\alpha 35.5$ $(10.25-46) \mathrm{pg} / \mathrm{ml})$ vs. $26(10.55-49) \mathrm{pg} / \mathrm{ml}$ vs. $5.1(1.1-4.3) \mathrm{pg} / \mathrm{ml} ; \mathrm{p}$ $<0.001$ ]; E-selectin [4.05 (2.0-5.8) ng/ml) vs. $2.1(1.0-3.8) \mathrm{ng} / \mathrm{ml}$ vs. $2(1,2) \mathrm{ng} / \mathrm{ml} ; \mathrm{p}<0.001] ;$ P-selectin $[6.5(3-8.9) \mathrm{ng} / \mathrm{ml})$ vs. 4.5 $(2-6.8) \mathrm{ng} / \mathrm{ml}$ vs. 3,1 (2.1-4) ng/ml; $\mathrm{p}<0.001]$; VICAM-1 [18 $(12.1-23) \mathrm{ng} / \mathrm{ml})$ vs. $16(10.1-20) \mathrm{ng} / \mathrm{ml}$ vs. 10 (7-15) ng/ml; $\mathrm{p}<$ 0.001]; ICAM-1 [17.8 (12.2-20) ng/ml) vs. $13.5(12.2-20) \mathrm{ng} / \mathrm{ml} v s$. 10.9 (12- 16.1) ng/ml; $\mathrm{p}<0.001]$; vWF [17.8 (12.2-20) ng/ml) vs. 13.5 (12.2-20) ng/ml vs. 10.9 (12-16.1) ng/ml; $\mathrm{p}<0.001]$; PAI-1 [137 (99.5-155) vs. 23(11-24) ng/ml vs. 10.915 (7-22) and lower median plasma values of IL-10 [ $11(6-15) \mathrm{pg} / \mathrm{ml}) v s .4(3-9) \mathrm{pg} / \mathrm{ml}$ vs. $2(1-5) \mathrm{pg} / \mathrm{ml} ; \mathrm{p}<0.001]$. Among subjects with acute ischemic stroke we observed higher plasma values of CRP, IL-1 $\beta$, IL-6, TNF- $\alpha$, E-Selectin, P-Selectin, ICAM-1, VCAM-1, wWF, PAI-1 in subjects with LAAS, lacunar and CEI subtype ischemic stroke and metabolic syndrome compared to subjects with this subtype of stroke without metabolic syndrome. Furthermore, in subjects with acute ischemic stroke and metabolic syndrome compared to subjects with acute ischemic stroke without metabolic syndrome we observed a more significant positive correlation for age, and gender, between PWV and CRP $(\mathrm{r}=0.38$ vs. $\mathrm{r}=0.31 ; \mathrm{p}=0.021)$; TNF- $\alpha(\mathrm{r}$ $=0.44$ vs. $\mathrm{r}=0.34 \mathrm{p}<0.05), \operatorname{IL} 1 \beta(\mathrm{r}=0.39$ vs. $\mathrm{r}=0.30 ; \mathrm{p}<<0.05)$, IL-6 $(\mathrm{r}=0.42$ vs. $\mathrm{r}=0.35 \mathrm{p}=0.032)$, Eselectin $(\mathrm{r}=0.36$ vs. $\mathrm{r}=$ $0.29 ; \mathrm{p}=0.038)$, P-selectin $(\mathrm{r}=0.34$ vs. $\mathrm{r}=0.28 ; \mathrm{p}=0.041)$, and IL-6 $(\mathrm{r}=0.21 ; \mathrm{P}<0.05)$, vWF $(\mathrm{r}=0.40$ vs. $\mathrm{r}=0.34 ; \mathrm{p}=0.019)$, PAI-1 $(\mathrm{r}=0.37 v s . \mathrm{r}=0.29 ; \mathrm{p}<0.05)$. Other interesting findings come from a study in which we assessed plasma levels of immunoinflammatory variables in patients with cardio- embolic acute ischaemic stroke compared to other diagnostic subtypes and to evaluate the relationship between immuno- inflammatory variables, acute neurological deficit and brain infarct volume [151]. Patients with ischaemic stroke classified as cardio-embolic (CEI) showed, compared to other subtypes, significantly higher median plasma levels of TNF- $\alpha$ [38.5 (22.2-46) pg/ml; $\mathrm{p}<0.0001]$, IL-6 [11 (5.519) $\mathrm{pg} / \mathrm{ml} ; \mathrm{p}=0.0029]$, IL1- $\beta$ [11.5 (8-13) $\mathrm{pg} / \mathrm{ml} ; \mathrm{p}<0.0001]$. Furthermore stroke patients classified as lacunar showed, compared to other subtypes, significantly lower median plasma levels of TNF- $\alpha$ [19.4 (9-23) pg/ml; p< 0.0001]; IL-6 [(4 (2-9) pg/ml; p=0.0029)], IL1- $\beta[6(10-3) \mathrm{pg} / \mathrm{ml}(\mathrm{p}<0.0001)]$ [151]. Multiple linear regression showed a significant association between the Scandinavian Stroke Scale (SSS) score at admission and diagnostic subtype: lacunar $(b=3.206 ; p=0.0338)$ ] or [cardio-embolic $(b=-7.819 ; p=0.0006)$ ], infarct volume of cardio-embolic strokes and some inflammatory variable $[$ TNF- $\alpha$ (b =-0.013; $p<0.0001)$ or IL-6 $(b=-0.074 ; p<$ $0.000) 1]$. Our findings confirm that cardio-embolic strokes have a worse clinical presentation and produce larger and more disabling strokes than other ischaemic stroke subtypes reporting a possible explanation of higher immuno-inflammatory activation of the acute phase.

Finally we conducted a study to investigate the relationship between immunoinflammatory markers and indexes of arterial stiffness in patients with seronegative spondyloarthritis (SpA) [152]. We enrolled 53 patients with $\mathrm{SpA}$ and 55 control subjects. After adjustment for blood glucose, cholesterol, and triglyceride levels, and systolic (SBP) and diastolic blood pressure (DBP), patients with seronegative SpA showed higher mean PWV $(9.98 \pm 2.9$ vs. $6.79 \pm 3.1 \mathrm{~m} / \mathrm{s}, \mathrm{p}<0.05)$ and Aix $(94.3 \pm 3.5 \%$ vs. $88 \pm 4.6 \%)$ compared to controls. Moreover, in patients with seronegative SpA, we observed higher mean plasma levels of IL-6 (8.21 vs. 6.14 $\mathrm{pg} / \mathrm{mL}, \mathrm{p}=0.011)$, IL-1 $\beta$ (4.11 vs. $2.14 \mathrm{pg} / \mathrm{mL}, \mathrm{p}=0.032)$, and TNF- $\alpha(31.11 v s .10 .74 \mathrm{pg} / \mathrm{mL}, \mathrm{p}<0.001)$ in subjects with mean $\mathrm{PWV}>8 \mathrm{~m} / \mathrm{s}$ in comparison with those with $\mathrm{PWV}<8 \mathrm{~m} / \mathrm{s}$ [152]. Multivariate analysis revealed a significant association between $\mathrm{PWV}>8 \mathrm{~m} / \mathrm{s}$ and male gender (OR 1.45, 95\% CI 0.98-2.77, $\mathrm{p}=$ 0.044 ), age (OR 3.09, 95\% CI 2.21-4.01, p < 0.001), diabetes (OR $2.86,95 \%$ CI 1.21-3.69, $\mathrm{p}=0.032$ ), hypertension (OR 3.01, 95\% CI 2.01-4.01, p < 0.005), LDL-C levels > $120 \mathrm{mg} / \mathrm{dL}(\mathrm{OR} 1.85,95 \%$ CI 1.12-2.88, $\mathrm{p}=0.038$ ), plasma TC levels $>200 \mathrm{mg} / \mathrm{dL}$ (OR 1.72 , 95\% CI 1.01-2.35, $\mathrm{p}=0.041$ ), CAD (OR 2.43, 95\% CI 1.31-2.87, $1.31-2.87, \mathrm{p}=0.023$ ), microalbuminuria (OR $2.51,95 \%$ CI $1.24-$ $2.79, \mathrm{p}=0.020)$, carotid plaque (OR 2.91, 95\% CI 1.54-4.01, $\mathrm{p}=$ 0.027 ), IL-6 (OR 3.09, 95\% CI 2.02-5.01, $\mathrm{p}=0.009$ ), IL-1 $\beta$ (OR $3.11,95 \%$ CI 1.54-4.01, $\mathrm{p}<0.05$ ), and TNF- $\alpha$ (OR 3.99, 95\% CI $3.17-5.33, \mathrm{p}<0.001)$. These findings emphasize the role of inflammatory variables and metabolic factors in indexes of high arterial stiffness. Thus, an inflammatory-metabolic background may influence the pathogenesis of increased arterial stiffness in seronegative inflammatory arthritis.

\section{CONCLUSION}

As we have seen, each surrogate marker has its importance from the pathophysiological and clinical point of view, and those can also be good therapeutic targets. However, it must be stressed that assessments of these vascular markers are not mutually exclusive, but rather complementary and those can offer different views of the same pathology. Therefore, the further simultaneous evaluation of these surrogate markers in the context of cardiovascular diseases will allow us a better comprehension of these complex diseases with the prospect of being able to offer the most appropriate treatment options for each patient. Nevertheless relationship between inflammation, inflammatory cell involvement and arterial stiffness [153-159] pathogenesis is a issue to address in future studies

\section{CONFLICT OF INTEREST}

The authors confirm that this article content has no conflict of interest.

\section{ACKNOWLEDGEMENTS}

Declared none.

\section{REFERENCES}

[1] Controlled Clinical Trials. 2001; 22: 485-502.

[2] Cohn JN. Introduction to Surrogate Markers. Circ Am Heart Assoc 2004; 10925 (Suppl 1): IV20-1.

[3] Fleming T, David D. Surrogate end points in clinical trials: are we being misled? Ann Intern Med 1996; 125(7): 605-13.

[4] The role of vascular biomarkers for primary and secondary prevention. A position paper from the European Society of Cardiology Working Group on peripheral circulation Endorsed by the Association for Research into Arterial Structure and Physiology (ARTERY) Society.

[5] Stampfer MJ, Ridker PM, Dzau VJ. Risk factor criteria. Circulation 2004; 109(Suppl 1): IV3-5.) (Manolio T. Novel risk markers and clinical practice. N Engl J Med 2003; 349: 1587-9.

[6] Grundy SM, Pasternak R, Greenland P, Smith S Jr., Fuster V. Assessment of cardiovascular risk by use of multiple-risk-factor assessment equations: A statement for healthcare professionals from the American Heart Association and the American College of Cardiology. Circulation 1999; 100: 1481-92.

[7] Wilson PW, D'Agostino RB, Levy D, Belanger AM, Silbershatz H, Kannel WB. Prediction of coronary heart disease using risk factor categories. Circulation 1998; 97: 1837-47.

[8] Kroeker EJ, Wood EH. Comparison of simultaneously recorded central and peripheral arterial pressure pulses during rest, exercise and tilted position in man. Circ Res 1955; 3: 623-32. 
[9] Ohte N, Saeki T, Miyabe H, et al. Relationship between blood pressure obtained from the upper arm with a cuff-type sphygmomanometer and central blood pressure measured with a catheter-tipped micromanometer. Heart Vessels 2007; 22: 410-5.

[10] Carmel M. McEniery, John R. Cockcroft, Mary J. Roman, Stanley S. Franklin, Ian B. Wilkinson, Central blood pressure: current evidence and clinical importance DOI: http: //dx.doi.org/10.1093/eurheartj/eht565 eht565 First published online: 23 January 2014.

[11] Nichols WW, ORourke MF, Vlachopoulos C. McDonald's Blood Flow in Arteries, Hodder Arnold, London, 2011.

[12] Avolio Ap, Van Bortel LM, Boutouyrie P, et al. Role of pulse pressure amplification in arterial hypertension: experts' opinion and review of the data, Hypertension 2009; 54: 375-83.

[13] Namasivayam M, McDonnell BJ, McEniery CM, O'Rourke MF. Anglo-Cardiff Collaborative Trial Study I. Does wave reflection dominate age-related change in aortic blood pressure across the human life span? Hypertension 2009; 53: 979-85.

[14] Laurent S, Cockcroft J, Van Bortel L, et al. Expert consensus document on arterial stiffness: methodological issues and clinical applications. Eur Heart J 2006; 27: 2588-605.

[15] Adams HP, Bendixen BH, Kappelle J, et al. Classification of subtype of acute ischemic stroke. Stroke 1993; e24: 358.

[16] Tuttolomondo A, Di Sciacca R, Di Raimondo D, et al. Arterial stiffness indexes in acute ischemic stroke: relationship with stroke subtype. Atherosclerosis 2010; 211(1): 187-94.

[17] Avolio AP, Chen SG, Wang RP, Zhang CL, Li MF, O'Rourke MF. Effects of aging on changing arterial compliance and left ventricular load in a northern Chinese urban community. Circulation 1983; 68: $50-8$.

[18] O'Rourke MF, Hashimoto J. Mechanical factors in arterial aging: a clinical perspective. J Am Coll Cardiol 2007; 50: 1-13.

[19] Wang M, Lakatta EG. Altered regulation of matrix metalloproteinase-2 in aortic remodeling during aging. Hypertension 2002; 39 : 865-73.

[20] Role of arterial stiffness in cardiovascular disease Marina Cecelja, Phil Chowienczyk King's College London British Heart Foundation Centre, Department of Clinical Pharmacology, St Thomas' Hospital, London, UK

[21] Scuteri A, Najjar SS, Muller DC, et al. Metabolic syndrome amplifies the age-associated increases in vascular thickness and stiffness. J Am Coll Cardiol 2004; 43: 1388-95.

[22] Cecelja M, Chowienczyk P. Dissociation of aortic pulse wave velocity with risk factors for cardiovascular disease other than hypertension: a systematic review. Hypertension 2009; 54: 1328-36.

[23] Benetos A, Adamopoulos C, Bureau JM, et al. Determinants of accelerated progression of arterial stiffness in normotensive subjects and in treated hypertensive subjects over a 6-year period. Circulation 2002; 105: 1202-7.

[24] Blacher J, Asmar R, Djane S, London GM, Safar ME. Aortic pulse wave velocity as a marker of cardiovascular risk in hypertensive patients. Hypertension 1999; 33: 1111-7.

[25] Yasmin, McEniery CM, Wallace S, Mackenzie IS, Cockcroft JR, Wilkinson IB. C-reactive protein is associated with arterial stiffness in apparently healthy individuals. Arterioscler Thromb Vasc Biol 2004; $24:$ 969-74.

[26] Oliver JJ, Webb DJ. Noninvasive assessment of arterial stiffness and risk of atherosclerotic events. Arterioscler Thromb Vasc Biol 2003; 23: 554-66.

[27] Bank AJ, Kaiser DR, Rajala S, Cheng A. In vivo human brachial artery elastic mechanics: Effects of smooth muscle relaxation. Circulation 1999; 100: 41-7.

[28] Mahmud A, Feely J. Reduction in arterial stiffness with angiotensin II antagonist is comparable with and additive to ACE inhibition. Am J Hypertens 2002; 15: 321-5.

[29] Safar ME, London GM, Asmar RG, Hughes CJ, Laurent SA. An indirect approach for the study of the elastic modulus of the brachial artery in patients with essential hypertension. Cardiovasc Res 1986; 20: 563-7.

[30] Shige H, Dart A, Nestel P. Simvastatin improves arterial compliance in the lower limb but not in the aorta. Atherosclerosis 2001; 155: $245-50$.

[31] Smilde TJ, van den Berkmortel FW, Wollersheim H, van Langen H, Kastelein JJ, Stalenhoef AF. The effect of cholesterol lowering on carotid and femoral artery wall stiffness and thickness in patients with familial hypercholesterolaemia. Eur J Clin Invest 2000; 30: 473-80.

[32] Vita JA, Keaney JF. Endothelial function: a barometer for cardiovascular risk. Circulation 2002; 106: 640-2.

[33] Verma S, Anderson TJ. Fundamentals of endothelial function for the clinical cardiologist. Circulation 2002; 105: 546-9.

[34] Ross R. The pathogenesis of atherosclerosis: a perspective for the 1990s. Nature 1993; 362: 801-09.

[35] Schechter AN, Gladwin MT. Hemoglobin and the paracrine and endocrine functions of nitric oxide. N Engl J Med 2003; 348: 14835.

[36] Furchgott RF, Zawadzki JV. The obligatory role of endothelial cells in the relaxation of arterial smooth muscle by acetylcholine. Nature 1980; 288: 373-6.

[37] Corson MA, James NL, Latta SE, Nerem RM, Berk BC, Harrison DG. Phosphorylation of endothelial nitric oxide synthase in response to fluid shear stress. Circ Res 1996; 79: 984-91.

[38] Forstermann U, Munzel T. Endothelial nitric oxide synthase in vascular disease: from marvel to menace. Circulation 2006; 113 1708-14.

[39] Anderson TJ. Assessment and treatment of endothelial dysfunction in humans. J Am Coll Cardiol 1999; 34: 631-8.

[40] Moncada S, Higgs EA, Vane JR. Human arterial and venous tissues generate prostacyclin (prostaglandin $\mathrm{x}$ ), a potent inhibitor of platelet aggregation. Lancet 1977; 1: 18 -20.

[41] Saye JA, Singer HA, Peach MJ. Role of endothelium in conversion of angiotensin I to angiotensin II in rabbit aorta. Hypertension 1984; 6: 216-21.

[42] Kinlay S, Behrendt D, Wainstein M, et al. Role of endothelin-1 in the active constriction of human atherosclerotic coronary arteries. Circulation 2001; 104: 1114-8.

[43] Lekakis J, Abraham P, Balbarini A, et al. Methods for evaluating endothelial function: a position statement from the European Society of Cardiology Working Group on Peripheral Circulation, Eur J Cardiovasc Prev Rehabil 2011; 18: 775-89.

[44] Corretti MC, Anderson TJ, Benjamin EJ, et al. Guidelines for the ultrasound assessment of endothelial-dependent flow-mediated vasodilation of the brachial artery: a report of the International Brachial Artery Reactivity Task Force, J. Am. Coll. Cardiol. 39 (2002) 257e265.

[45] Doshi SN, Naka KK, Payne N, et al. Flow-mediated dilatation following wrist and upper arm occlusion in humans: the contribution of nitric oxide. Clin Sci (Lond.) 2001; 101: 629-35.

[46] Mannion TC, Vita JA, Keaney JF Jr., Benjamin EJ, Hunter L, Polak JF. Non-invasive assessment of brachial artery endothelial vasomotor function: the effect of cuff position on level of discomfort and vasomotor responses. Vasc Med 1998; 3: 263-7.

[47] Uehata A, Lieberman EH, Gerhard MD, et al. Noninvasive assessment of endothelium-dependent flow-mediated dilation of the brachial artery. Vasc Med 1997; 2: 87-92.

[48] Vogel RA, Corretti MC, Plotnick GD. A comparison of the assessment of flow-mediated brachial artery vasodilation using upper versus lower arm arterial occlusion in subjects with and without coronary risk factors. Clin Cardiol 2000; 23: 571-5.

[49] Neunteufl T, Katzenschlager R, Hassan A, et al. Systemic endothelial dysfunction is related to the extent and severity of coronary artery disease. Atherosclerosis 1997; 129: 111-8.

[50] Teragawa H, Ueda K, Matsuda K, et al. Relationship between endothelial function in the coronary and brachial arteries. Clin Cardiol 2005; 28: 460-6.

[51] Anderson TJ, Uehata A, Gerhard MD, et al. Close relation of endothelial function in the human coronary and peripheral circulations. $J$ Am Coll Cardiol 1995; 26: 1235-41.

[52] Takase B, Hamabe A, Satomura K, et al. Comparable prognostic value of vasodilator response to acetylcholine in brachial and coronary arteries for predicting long-term cardiovascular events in suspected coronary artery disease. Circ J 2006; 70: 49-56.

[53] Charakida M, Masi S, Luscher TF, Kastelein JJ, Deanfield JF. Assessment of atherosclerosis: the role of flow-mediated dilatation. Eur Heart J 2010; 31: 2854-61.

[54] Briet M, Collin C, Laurent S, et al. Endothelial function and chronic exposure to air pollution in normal male subjects. Hypertension 2007; 50: 970-6.

[55] Modena MG, Bonetti L, Coppi F, Bursi F, Rossi R. Prognostic role of reversible endothelial dysfunction in hypertensive postmenopausal women. J Am Coll Cardiol 2002; 40: 505-10. 
[56] Landmesser U, von Eckardstein A, Kastelein J, Deanfield J, Luscher TF. Increasing high-density lipoprotein cholesterol by cholesteryl ester transfer protein-inhibition: a rocky road and lessons learned? The early demise of the dal-HEART programme. Eur Heart J 2012; 33: 1712-5.

[57] Kitta Y, Obata JE, Nakamura T, et al. Persistent impairment of endothelial vasomotor function has a negative impact on outcome in patients with coronary artery disease. J Am Coll Cardiol 2009; 53: $323-30$.

[58] Levenson J, Pessana F, Gariepy J, Armentano R, Simon A. Gender differences in wall shear-mediated brachial artery vasoconstriction and vasodilation. J Am Coll Cardiol 2001; 38: 1668-74.

[59] Spieker LE, Luscher TF, Noll G. ETA receptors mediate vasoconstriction of large conduit arteries during reduced flow in humans. J Cardiovasc Pharmacol 2003; 42: 315-8.

[60] Gori T, Dragoni S, Lisi M, et al. Conduit artery constriction mediated by low flow a novel noninvasive method for the assessment of vascular function. J Am Coll Cardiol 2008; 51: 1953-8.

[61] Gori T, Muxel S, Damaske A, et al. Endothelial function assessment: flow-mediated dilation and constriction provide different and complementary information on the presence of coronary artery disease. Eur Heart J 2012; 33(3): 363-71.

[62] Hamburg NM, Palmisano J, Larson MG, et al. Relation of brachial and digital measures of vascular function in the community: the Framingham heart study, Hypertension 2011; 57: 390-6.

[63] Schnabel RB, Schulz A, Wild PS, et al. Noninvasive vascular function measurement in the community: cross-sectional relations and comparison of methods, Circ. Cardiovasc Imaging 2011; 4: 371-80.

[64] Kuvin JT, Patel AR, Sliney KA, et al. Assessment of peripheral vascular endothelial function with finger arterial pulse wave amplitude. Am Heart J 2003; 146: 168-74.

[65] Flammer AJ, Anderson T, Celermajer DS, et al. The assessment of endothelial function: from research into clinical practice. Circulation 2012; 126: 753-67.

[66] Rosenbaum D, Giral P, Chapman J, et al. Radial augmentation index is a surrogate marker of atherosclerotic burden in a primary prevention cohort. Atherosclerosis 2013. PMID: 24267263.

[67] Muiesan ML, Salvetti M, Rizzoni D, et al. Pulsatile hemodynamics and microcirculation: evidence for a close relationship in hypertensive patients. Hypertension 2013; 61: 130-6.

[68] Hashimoto J, Aikawa T, Imai Y. Large artery stiffening as a link between cerebral lacunar infarction and renal albuminuria. Am J Hypertens 2008; 21: 1304-9.

[69] Brisset M, Boutouyrie P, Pico F, et al. Large-vessel correlates of cerebral small-vessel disease. Neurology 2013; 80: 662-9.

[70] Ott C, Raff U, Harazny JM, Michelson G, Schmieder RE. Central pulse pressure is an independent determinant of vascular remodeling in the retinal circulation. Hypertension 2013; 61: 1340-5.

[71] Laurent S, Briet M, Boutouyrie P. Large and small artery cross-talk and recent morbidity-mortality trials in hypertension, Hypertension 54 (2009) 388e392.

[72] Park JB, Schiffrin EL. Small artery remodeling is the most prevalent (earliest?) form of target organ damage in mild essential hypertension, J. Hypertens 19 (2001) 921e930.

[73] Li H, Cybulsky MI, Gimbrone MA Jr., et al. An atherogenic diet rapidly induces VCAM-1, a cytokine regulatable mononuclear leukocyte adhesion molecule, in rabbit endothelium. Arterioscler Thromb 1993; 13: 97-204.

[74] Cybulsky MI, Iiyama K, Li H, et al. A major role for VCAM-1, but not ICAM-1, in early atherosclerosis. J Clin Invest 2001; 107: 1255-62.

[75] Topper JN, Cai J, Falb D, et al. Identification of vascular endothelial genes differentially responsive to fluid mechanical stimuli: cyclooxygenase-2, manganese superoxide dismutase, and endothelial cell nitric oxidesynthase are selectively up-regulated by steady laminar shear stress. Proc Natl Acad Sci USA 1996; 93: 10417-22.

[76] De Caterina R, Libby P, Peng HB, et al. Nitric oxide decreases cytokineinduced endothelial activation: nitric oxide selectively reduces endothelial expression of adhesion molecules and proinflammatory cytokines. J Clin Invest 1995; 96: 60-8.

[77] Nagel T, Resnick N, Atkinson WJ, et al. Shear stress selectively upregulates intercellular adhesion molecule-1 expression in cultured human vascular endothelial cells. J Clin Invest 1994; 94: 885-91.

[78] Gu L, Okada Y, Clinton S, et al. Absence of monocyte chemoattractant protein-1 reduces atherosclerosis in low-density lipoprotein-deficient mice. Mol Cell 1998; 2: 275-81.
[79] Boring L, Gosling J, Cleary M, et al. Decreased lesion formation in CCR2-/- mice reveals a role for chemokines in the initiation of atherosclerosis. Nature 1998; 394: 894-7.

[80] Mach F, Sauty A, Iarossi A, et al. Differential expression of three T lymphocyte-activating CXC chemokines by human atheromaassociated cells. J Clin Invest 1999; 104: 1041-50.

[81] Smith JD, Trogan E, Ginsberg M, et al. Decreased atherosclerosis in mice deficient in both macrophage colony-stimulating factor (op) and apolipoprotein E. Proc Natl Acad Sci USA 1995; 92: 8264-8.

[82] Qiao JH, Tripathi J, Mishra NK, et al. Role of macrophage colonystimulating factor in atherosclerosis: studies of osteopetrotic mice. Am J Pathol 1997; 150: 1687-99.

[83] Hansson G, Libby P. The role of the lymphocyte. In: Fuster V, Ross R, Topol E, eds. Atherosclerosis and Coronary Artery Disease. New York, NY: Lippincott-Raven; 1996: 557-68.

[84] Ross R. Atherosclerosis: an inflammatory disease. N Engl J Med 1999; 340: 115-26.

[85] Fraley AE, Tsimikas S. Clinical applications of circulating oxidized lowdensity lipoprotein biomarkers in cardiovascular disease. Curr Opin Lipidol 2006; 17: 502-9.

[86] Landmesser U. High density lipoprotein - should we raise it? Curr Vasc Pharmacol 2012; 10: 718-9.

[87] Inoue T, Kato T, Uchida T, et al. Local release of C-reactive protein from vulnerable plaque or coronary arterial wall injured by stenting. J Am Coll Cardiol 2005; 46: 239-45.

[88] Liuzzo G, Biasucci LM, Gallimore JR, et al. The prognostic value of C-reactive protein and serum amyloid a protein in severe unstable angina. N Engl J Med 1994; 331: 417-24.

[89] Biasucci LM, Liuzzo G, Colizzi C, et al. Clinical use of C-reactive protein for the prognostic stratification of patients with ischemic heart disease. Ital Heart J 2001; 2: 164-71.

[90] Ridker PM, Hennekens CH, Buring JE, et al. C-reactive protein and other markers of inflammation in the prediction of cardiovascular disease in women. N Engl J Med 2000; 342: 836-43.

[91] Ridker PM, Rifai N, Stampfer MJ, et al. Plasma concentration of interleukin- 6 and the risk of future myocardial infarction among apparently healthy men. Circulation 2000; 101: 1767-72.

[92] Harris TB, Ferrucci L, Tracy RP, et al. Associations of elevated interleukin-6 and C-reactive protein levels with mortality in the elderly. Am J Med 1999; 106: 506-12.

[93] Ridker PM, Rifai N, Pfeffer M, et al. Elevation of tumor necrosis factor- $\alpha$ and increased risk of recurrent coronary events after myocardial infarction. Circulation 2000; 101: 2149-53.

[94] Hwang SJ, Ballantyne CM, Sharrett AR, et al. Circulating adhesion molecules VCAM-1, ICAM-1, and E-selectin in carotid atherosclerosis and incident coronary heart disease cases. The Atherosclerosis Risk in Communities (ARIC) study. Circulation 1997; 96: 4219-25.

[95] Ridker PM, Hennekens CH, Roitman-Johnson B, et al. Plasma concentration of soluble intercellular adhesion molecule 1 and risks of future myocardial infarction in apparently healthy men. Lancet 1998; 351: 88-92.

[96] Ridker PM, Buring JE, Rifai N. Soluble P-selectin and the risk of future cardiovascular events. Circulation 2001; 103: 491-5.

[97] Tuttolomondo A, Di Raimondo D, Pecoraro R, et al. Immuneinflammatory markers and arterial stiffness indexes in subjects with acute ischemic stroke. Atherosclerosis 2010; 213: 311-8.

[98] Ridker PM, Cushman M, Stampfer MJ, et al. Inflammation, aspirin, and the risk of cardiovascular disease in apparently healthy men. $\mathrm{N}$ Engl J Med 1997; 336: 973-9.

[99] Haverkate F, Thompson SG, Pyke SD, et al. Production of Creactive protein and risk of coronary events in stable and unstable angina. European Concerted Action on Thrombosis and Disabilities Angina Pectoris Study Group. Lancet 1997; 349: 462-6.

[100] Kuller LH, Tracy RP, Shaten J, et al. Relation of C-reactive protein and coronary heart disease in the MRFIT nested case-control study. Multiple Risk Factor Intervention Trial. Am J Epidemiol 1996; 144: 537-47.

[101] Tracy RP, Lemaitre RN, Psaty BM, et al. Relationship of C-reactive protein to risk of cardiovascular disease in the elderly: results from the Cardiovascular Health Study and the Rural Health Promotion Project. Arterioscler Thromb Vasc Biol 1997; 17: 1121-7.

[102] Ridker PM, Buring JE, Shih J, et al. Prospective study of C-reactive protein and the risk of future cardiovascular events among apparently healthy women. Circulation 1998; 98: 731-3. 
[103] Danesh J, Whincup P, Walker M, et al. Low grade inflammation and coronary heart disease: prospective study and updated metaanalyses. BMJ 2000; 321: 199-204.

[104] Koenig W, Sund M, Frohlich M, et al. C-reactive protein, a sensitive marker of inflammation, predicts future risk of coronary heart disease in initially healthy middle-aged men: results from the MONICA (Monitoring Trends and Determinants in Cardiovascular Disease) Augsburg Cohort Study, 1984 to 1992. Circulation 1999; 99: 237-42.

[105] Pepys MB. C-reactive protein fifty years on. Lancet 1981; 1: 653-7.

[106] Meier-Ewert HK, Ridker PM, Rifai N, et al. Absence of diurnal variation of C-reactive protein concentrations in healthy human subjects. Clin Chem 2001; 47: 426-30.

[107] Rifai N, Tracy RP, Ridker PM. Clinical efficacy of an automated highsensitivity C-reactive protein assay. Clin Chem 1999; 45: 213641.

[108] Ridker PM. High-sensitivity C-reactive protein: potential adjunct for global risk assessment in the primary prevention of cardiovascular disease. Circulation 2001; 103: 1813-8.

[109] Ridker PM, Rifai N, Pfeffer MA, et al. Inflammation, pravastatin, and the risk of coronary events after myocardial infarction in patients with average cholesterol levels. Cholesterol and Recurrent Events (CARE) Investigators. Circulation 1998; 98: 839-44.

[110] Ridker PM, Rifai N, Pfeffer MA, et al. Long-term effects of pravastatin on plasma concentration of c-reactive protein. The Cholesterol and Recurrent Events (CARE) Investigators. Circulation 1999; 100: 230-5.

[111] Ridker PM, Rifai N, Lowenthal SP. Rapid reduction in C-reactive protein with cerivastatin among 785 patients with primary hypercholesterolemia. Circulation 2001; 103: 1191-3.

[112] Ridker PM, Rifai N, Clearfield M, et al. Measurement of C-reactive protein for the targeting of statin therapy in the primary prevention of acute coronary events. N Engl J Med 2001; 344: 1959-65.

[113] Albert MA, Danielson E, Rifai N, et al. Effect of statin therapy on C-reactive protein levels. The Pravastatin Inflammation/CRP Evaluation (PRINCE): a randomized trial and cohort study. JAMA 2001; 286: 64-70.

[114] Jialal I, Stein D, Balis D, et al. Effect of hydroxymethyl glutaryl coenzyme a reductase inhibitor therapy on high sensitive $\mathrm{C}$-reactive protein levels. Circulation 2001; 103: 1933-5.

[115] Downs JR, Clearfield M, Weis S, et al. Primary prevention of acute coronary events with lovastatin in men and women with average cholesterol levels: results of AFCAPS/TexCAPS. Air Force/Texas Coronary Atherosclerosis Prevention Study. JAMA 1998; 279: 1615-22.

[116] Libby P, Ridker PM, Maseri A. Inflammation in atherosclerosis. Arterioscler Thromb Vasc Biol 2012; 32(9): 2045-51.

[117] Kinlay S, Creager MA, Fukumoto M, et al. Endothelium-derived nitric oxide regulates arterial elasticity in human arteries in vivo. Hypertension 2001; 38: 1049-53.

[118] Schiffrin EL, Park JB, Intengan HD, Touyz RM. Correction of arterial structure and endothelial dysfunction in human essential hypertension by the angiotensin receptor antagonist losartan. Circulation 2000; 101: 1653-9.

[119] Hayward CS, Kraidly M, Webb CM, Collins P. Assessment of endothelial function using peripheral waveform analysis: A clinical application. J Am Coll Cardiol 2002; 40: 521-8.

[120] Wilkinson IB, Hall IR, MacCallum H, et al. Pulse-wave analysis: Clinical evaluation of a noninvasive, widely applicable method for assessing endothelial function. Arterioscler Thromb Vasc Biol 2002; 22: 147-52.

[121] Nigam A, Mitchell GF, Lambert J, Tardif JC. Relation between conduit vessel stiffness (assessed by tonometry) and endothelial function (assessed by flow-mediated dilatation) in patients with and without coronary heart disease. Am J Cardiol 2003; 92: 395-9.

[122] Mitchell GF, Parise H, Vita JA, et al. Local shear stress and brachial artery flow-mediated dilation: The Framingham Heart Study. Hypertension 2004; 44: 134-9. (Erratum 2005; 45: e9).

[123] Parker BA, Ridout SJ, Proctor DN. Age and flow-mediated dilation: a comparison of dilatory responsiveness in the brachial and popliteal arteries. Am J Physiol Heart Circ Physiol (2006); 291: H30439.

[124] Thijssen DH, van Bemmel MM, Bullens LM, et al. The impact of baseline diameter on flow-mediated dilation differs in young and older humans. Am J Physiol Heart Circ Physiol 2008; 295: H15948 .
[125] Weissgerber TL, Davies GA, Tschakovsky ME. Low flowmediated constriction occurs in the radial but not the brachial artery in healthy pregnant and nonpregnant women. J Appl Physiol (2010); 108: 1097-105.

[126] Harrison M, Parkhurst K, Tarumi T, Lin HF, Tanaka H. Low flowmediated constriction: prevalence, impact and physiological determinant. Clin Physiol Functional Imaging 2011. DOI: 10.1111/j.1475-097X.2011.01032.x.

[127] Sorensen KE, Celermajer DS, Spiegelhalter DJ, et al. Non-invasive measurement of human endothelium dependent arterial responses: accuracy and reproducibility. Br Heart J (1995); 74: 247-253.

[128] Takase B, Uehata A, Akima T, et al. Endothelium-dependent flowmediated vasodilation in coronary and brachial arteries in suspected coronary artery disease. Am J Cardiol 1998; 82: 1535-9.

[129] Pyke K, Green DJ, Weisbrod C, et al. Nitric oxide is not obligatory for radial artery flow-mediated dilation following release of 5 or 10 min distal occlusion. Am J Physiol Heart Circ Physiol 2010; 298: H119-26.

[130] Avolio AP, Deng FQ, Li WQ, et al. Effects of aging on arterial distensibility in populations with high and low prevalence of hypertension: comparison between urban and rural communities in China. Circulation (1985); 71: 202-10.

[131] O’Rourke MF, Staessen JA, Vlachopoulos C, Duprez D, Plante GE. Clinical applications of arterial stiffness; definitions and reference values. Am J Hypertens 2002; 15: 426-44.

[132] Wykretowicz A, Guzik P, Kasinowski R, et al. Augmentation index, pulse pressure amplification and superoxide anion production in patients with coronary artery disease. Int. J. Cardiol 2005; 99(2): $289 \mathrm{e} 94$.

[133] Ushio-Fukai M, Alexander RW, Akers M, et al. Reactive oxygen species mediate the activation of Akt/protein kinase B by angiotensin II in vascular smooth muscle cells. J. Biol. Chem 1999; 274(32): 22699-704.

[134] Rajagopalan S, Meng XP, Ramasamy S, Harrison DG, Galis ZS. Reactive oxygen species produced by macrophage-derived foam cells regulate the activity of vascular matrix metalloproteinases in vitro. Implications for atherosclerotic plaque stability. J Clin Invest 1996; 98(11): 2572-9.

[135] Delles C, Zimmerli LU, McGrane DJ, et al. Vascular stiffness is related to superoxide generation in the vessel wall. J Hypertens 2008; 26(5): 946-55.

[136] Al-Benna S, Hamilton CA, McClure JD, et al. Low-density lipoprotein cholesterol determines oxidative stress and endothelial dysfunction in saphenous veins from patients with coronary artery disease. Arterioscler Thromb Vasc Biol 2006; 26(1): 218-23.

[137] Guzik TJ, West NE, Black E, et al. Vascular superoxide production by NAD(P)H oxidase: association with endothelial dysfunction and clinical risk factors. Circ Res 2000; 86(9): E85-90.

[138] Montero I, Orbe J, Varo N, et al. C-reactive protein induces matrix metalloproteinase-1 and -10 in human endothelial cells: implications for clinical and subclinical atherosclerosis. J Am Coll Cardiol 2006; 47(7): 1369-78.

[139] Dzau VJ, Braun-Dullaeus RC, Sedding DG. Vascular proliferation and atherosclerosis: new perspectives and therapeutic strategies. Nat. Med 2002; 8(11): 1249-56.

[140] Chai S, Chai Q, Danielsen CC, et al. Overexpression of hyaluronan in the tunica media promotes the development of atherosclerosis. Circ Res 2005; 96(5): 583-91.

[141] Kaji T, Hiraga S, Yamamoto C, et al. Tumor necrosis factor alphainduced alteration of glycosaminoglycans in cultured vascular smooth-muscle cells. Biochim Biophys Acta 1993; 1176(1e2): 206.

[142] Schnabel R, Larson MG, Dupuis J, et al. Relations of inflammatory biomarkers and common genetic variants with arterial stiffness and wave reflection. Hypertension 2008; 51(6): 1651-7.

[143] Yasmin, McEniery CM, Wallace S, Mackenzie IS, Cockcroft JR, Wilkinson IB. Creactive protein is associated with arterial stiffness in apparently healthy individuals. Arterioscler Thromb Vasc Biol 2004; 24(5): 969-74.

[144] Mattace-Raso FU, van der Cammen TJ, van der Meer IM, et al. Creactive protein and arterial stiffness in older adults: the Rotterdam study. Atherosclerosis 2004; 176(1): 111-6.

[145] Gunnett CA, Lund DD, McDowell AK, Faraci FM, Heistad DD. Mechanisms of inducible nitric oxide synthase-mediated vascular dysfunction. Arterioscler Thromb Vasc Biol 2005; 25(8): 1617-22. 
[146] Venugopal SK, Devaraj S, Yuhanna I, Shaul P, Jialal I. Demonstration that Creactive protein decreases eNOS expression and bioactivity in human aortic endothelial cells. Circulation 2002; 106(12): $1439-41$.

[147] Jain S, Khera R, Corrales-Medina VF, Townsend RR, Chirinos JA. Inflammation and arterial stiffness in humans. Atherosclerosis 2014; 237: 381-90.

[148] Sampaio RR, Ladeiaa AM, Meneses RB, Lima ML, Guimaraesa AC. C-Reactive Protein Is Not Correlated With Endothelial Dysfunction in Overweight and Obese Women. J Clin Med Res 2013; 5(4): 294-9.

[149] Tuttolomondo A, Di Raimondo D, Di Sciacca R, et al. Arterial stiffness and ischemic stroke in subjects with and without metabolic syndrome. Atherosclerosis 2012; 225: 216-9.

[150] Tuttolomondo A, Pecoraro R, Di Raimondo D, et al. Immuneinflammatory markers and arterial stiffness indexes in subjects with acute ischemic stroke with and without metabolic syndrome. Diabetology \& Metabolic Syndrome 2014, 6: 28 (http: //www.dmsjournal.com/content/6/1/28).

[151] Licata G, Tuttolomondo A, Di Raimondo D, Corrao S, Di Sciacca $\mathrm{R}$, Pinto A. Immuno-inflammatory activation in acute cardioembolic strokes in comparison with other subtypes of ischaemic stroke. Thromb Haemost 2009; 101: 929-37.

[152] Tuttolomondo A, Pecoraro R, Buttà C, et al. Arterial stiffness indexes and serum cytokine levels in seronegative spondyloarthritis: relationships between stiffness markers and metabolic and immunoinflammatory variables. Scand J Rheumatol 2015; 44: 474-9.
[153] Pinto A, Di Raimondo D, Tuttolomondo A, Buttà C, Milio G, Licata G. Effects of physical exercise on inflammatory markers of atherosclerosis. Curr Pharm Des 2012; 18(28): 4326-49.

[154] Pinto A, Tuttolomondo A, Di Raimondo D, et al. Cardiovascular risk profile and morbidity in subjects affected by type 2 diabetes mellitus with and without diabetic foot.Metabolism 2008; 57(5): 676-82.

[155] Tuttolomondo A, Pecoraro R, Pinto A. Studies of selective TNF inhibitors in the treatment of brain injury from stroke and trauma: a review of the evidence to date. Drug Des Devel Ther 2014; 8: 2221 38 .

[156] Tuttolomondo A, Pecoraro R, Casuccio A, et al. Peripheral frequency of CD4+ CD28- cells in acute ischemic stroke: relationship with stroke subtype and severity markers. Medicine (Baltimore) 2015; 94(20): e813.

[157] Albanese A, Tuttolomondo A, Anile C, et al. Spontaneous chronic subdural hematomas in young adults with a deficiency in coagulation factor XIII. Report of three cases. J Neurosurg 2005; 102(6): 1130-2.

[158] Petta S, Argano C, Colomba D, et al. Epicardial fat, cardiac geometry and cardiac function in patients with non-alcoholic fatty liver disease: association with the severity of liver disease. J Hepatol 2015; 62(4): 928-33.

[159] Parrinello G, Colomba D, Bologna P, et al. Early carotid atherosclerosis and cardiac diastolic abnormalities in hypertensive subjects.J Hum Hypertens 2004; 18(3): 201-5. 